\title{
A visão de família entre as adolescentes que sofreram violência intrafamiliar ${ }^{1}$
}

\author{
Clarissa De Antoni \\ Sílvia Helena Koller \\ Universidade Federal do Rio Grande do Sul
}

Resumo

Este estudo apresenta a visão de adolescentes sobre família. Doze adolescentes entre doze a dezessete anos, do sexo feminino, abrigadas em uma instituição pública após sofrerem maus tratos intrafamiliares, apresentaram sua visão sobre o conceito de família e suas expectativas em relação à constituição de suas próprias famílias no futuro, em dois grupos focais. $\mathrm{O}$ conteúdo dos grupos focais " $A$ " $e$ " $B$ " foram analisados separadamente, como contextos únicos. O grupo "A" apresentou uma visão de família, baseada em uma configuração por laços afetivos, onde a definição dos papéis e responsabilidades parentais são superpostos e indefinidos, e as inter-relações marcadas pela violência. $\mathrm{O}$ grupo "B" revela sua visão sobre a família com base no modelo tradicional, onde a configuração está centrada no grau de parentesco, com papéis parentais delimitados e as inter-relações marcadas pela reciprocidade. A idealização da família foi um aspecto predominante nos grupos. As expectativas sobre a formação de sua própria família no futuro estiveram presentes em ambos os grupos, mas com configuração e papéis diferentes dos atuais. Esta atitude pode ser vista como proteção frente às situações de risco às quais estão expostas em função da expectativa de mudança qualitativa nas relações familiares futuras.

Palavras-chave: Adolescentes, Proteção, risco, Família, Violência doméstica. 
Key words: Adolescence, Protective factors, Risk, Family, Domestic violence.

\section{Abstract}

Family view among adolescents who suffered intrafamilial violence

This study presents adolescents' point of view about family. Twelve female adolescents, 12 to 17 year old, institutionalized after being abused by their families, showed their family concepts, and their expectations about having a family in the future, in two focus groups. The focus groups "A" and "B" were analyzed, separately, as unique contexts. Focus group "A" revealed their point of view about family, based on emotional ties, where the parents' responsibilities and roles were overlapped, and the relationships were marked by violence. Focus group "B" revealed their point of view about family, based on a traditional related family, with pre determined parents' roles, and the relationships were marked by reciprocity. Both groups were marked by idealization of family. The expectations about having their own family in the future were presented in each group, but with different configuration and roles from the one they have now This attitude can be seem as a protective way against the risk situations they are living, and as a hope for change in their future.

definição do termo família encontrada na literatura tem por base os conceitos advindos da Antropologia, da Sociologia ou da Psicologia. Segundo Berenstein (1988), nas definições antropológicas, o foco de interesse do estudo sobre famílias consiste na estrutura das relações, isto é, o grau e a natureza do parentesco. A estrutura elementar de parentesco inclui três tipos de vínculos: o consangüíneo (entre irmãos), de aliança (marido e esposa) e de filiação (pais e filhos). As definições sociológicas centralizam-se em tipologia familiar, que inclui: família nuclear ou de orientação (composta por pai, mãe, os irmãos e as irmãs), família de procriação (formada pela pessoa, 
seu marido/esposa, filhos), entre outras configurações. A família pode ser compreendida a partir do número de integrantes e da sua extensão, que determinam mudanças estruturais e ampliações no tamanho e na forma do grupo familiar, isto é, as reorganizações depois de mortes, divórcios e novos casamentos.

As definições psicológicas descrevem o grupo familiar como um conjunto de relações. A família pode ser vista como totalidade, sistema ou grupo formado por pessoas que se relacionam entre si, por parentesco e/ou por se considerarem pertencentes àquele contexto. Tais relações, idealmente, se caracterizam por união e por influência recíproca direta, intensa e duradoura (Laing, 1983). De acordo com Minuchin (1982), a família é um sistema aberto e em transformação constante pela troca de informações com os sistemas extrafamiliares. As ações de cada um de seus membros são orientadas pelas características intrínsecas ao próprio sistema familiar, mas podem mudar diante das necessidades e das preocupações externas.

Similar idéia é fornecida pelo modelo ecológico do desenvolvimento humano (Bronfenbrenner, 1979/1996). Segundo este modelo, a família é uma unidade funcional, isto é, um microssistema, no qual as relações devem ser estáveis, recíprocas e com equilíbrio de poder entre os diversos papéis. O microssistema familiar é o primeiro sistema no qual o ser humano em desenvolvimento interage, e possui um padrão de papéis, de atividades e de relacionamentos que são associados a determinados comportamentos e expectativas, de acordo com a sociedade no qual está inserido. Como um sistema de encaixes contidos uns nos outros, o microssistema está inserido nos sistemas mais amplos que o influenciam e aos quais também influencia. Bronfenbrenner denominou os demais sistemas como: mesossistema, exossistema e macrossistema (ver Figura 1- Para efeito demonstrativo, esta figura está representada pela família nuclear, embora haja outras formas de configuração familiar). $\mathrm{O}$ mesossistema consiste na interrelação de dois ou mais ambientes, nos quais a pessoa/família em desenvolvimento participa ativamente. São exemplos as relações da família com a escola, com a vizinhança, com o ambiente de trabalho, com os grupos sociais, entre outros. Os processos experienciados 
nestes diversos contextos não são independentes uns dos outros, podendo promover ou dificultar o desenvolvimento do sistema familiar e de seus membros. A presença ou ausência de relações da família com a escola, por exemplo, pode afetar o desempenho escolar de uma criança, a expectativa de um sistema sobre o outro e os processos de comunicação entre eles (Bronfenbrenner, 1986; Garbarino, 1992; Gill, Reynolds \& Pai, 1995).

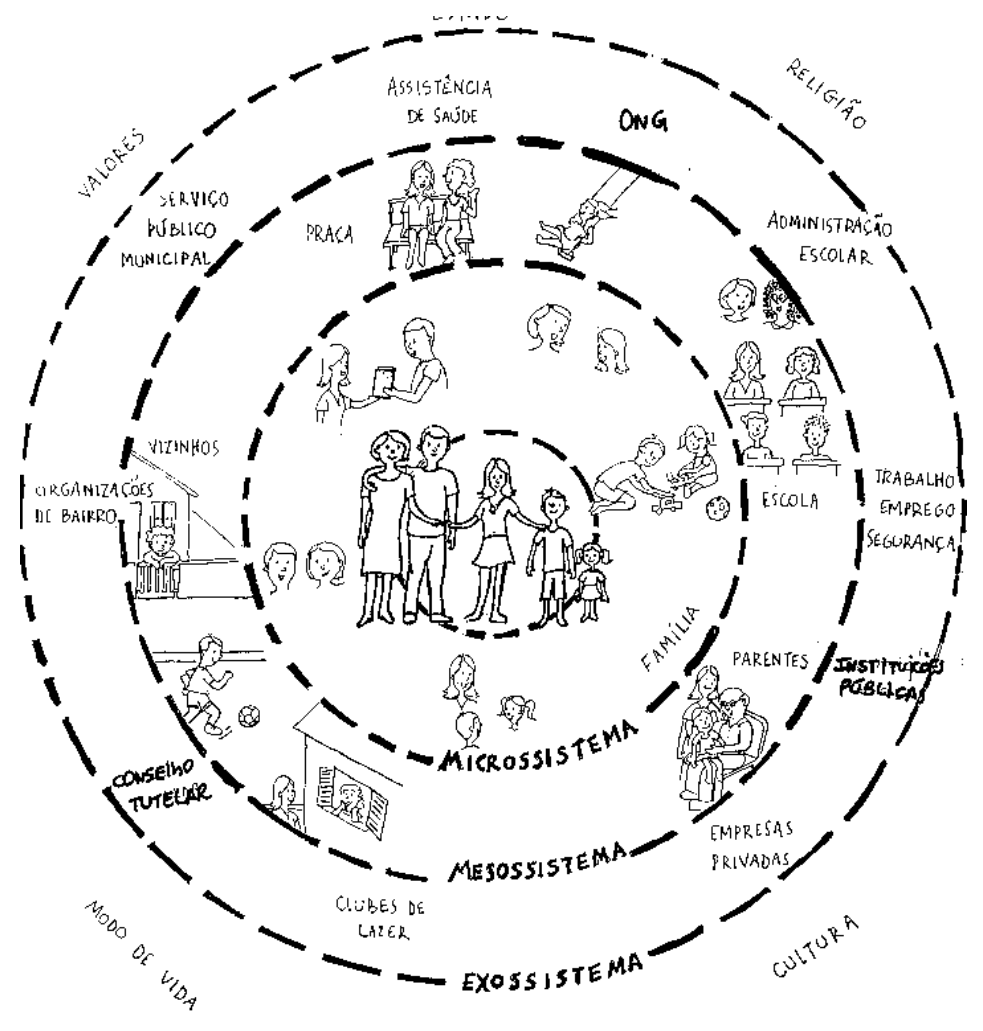

TDEOLOGIAS

MAGROSSISTEMA 
O exossistema é composto por ambientes nos quais apenas um ou mais membros da família mantém relações face a face, interagindo diretamente. No entanto, as relações deste integrante da família têm efeito sobre a família. Três sistemas têm sido enfatizados na análise do contexto ecológico familiar: o trabalho (enfoque social do trabalho/ desemprego), a rede de apoio social (com quem a família pode contar e quem pode contar com ela, ver Brito \& Koller, 1999), e a comunidade (grupos sociais, religiosos, culturais, legislativos; Bronfenbrenner, 1986). O macrossistema é o sistema mais amplo, que abrange aos demais. É composto pelo padrão global de ideologias, valores, crenças e organização social comum a uma determinada cultura ou subcultura (Bronfenbrenner, 1979/1996). A presença ou ausência de valorização da família, de políticas sociais para o combate à violência e a promoção da educação e saúde, de políticas econômicas para melhorar a qualidade de vida da população, são exemplos de macrossistema que têm reflexo direto no desenvolvimento do sistema familiar.

Estas visões de família revelam-na como um sistema integrado, que busca manter a estabilidade e o senso de equilíbrio em seus relacionamentos internos e externos, no decorrer de sua história. No entanto, também contemplam a possibilidade de que tal estabilidade possa ser ameaçada por mudanças e por períodos de desequilíbrio (crises imprevisíveis). Uma crise prevista, no decorrer do ciclo vital de desenvolvimento, pode ser exemplificada pela troca de funções e responsabilidades exercidas pelos pais em relação aos seus filhos. Durante a infância, os papéis familiares são, principalmente, de nutrição, de proteção e de socialização. Com a entrada na adolescência, o relacionamento e o funcionamento da família mudam. Os adolescentes necessitam mais apoio e orientação que o cuidado dedicado a eles anteriormente (Steinberg, 1996). No decorrer da vida, o relacionamento entre os pais e os filhos torna-se cada vez mais igualitário, podendo acarretar períodos de desequilíbrio na definição dos novos papéis, cuidados e responsabilidades (Cobb, 1992; Minuchin, 1982; Steinberg, 1996; Zamberlan, Camargo \& Biasoli-Alves, 1997). Uma crise imprevisível na vida familiar, como rompimentos, mortes, empobrecimento súbito, no entanto, exige força interna e apoio de sistemas 
externos, com os quais a família nem sempre pode contar, agravando as situações de risco.

Todas as definições de família até aqui apresentadas pressupõem uma visão de família organizada, que enfrenta eventos estressores, mas encontra recursos em si mesma ou no seu ambiente para retornar a um estado equilibrado. No entanto, nem sempre é esta a situação verificada nos grupos familiares, indicando que tais definições baseiam-se em uma visão idealizada do sistema familiar. Os estudos, cada vez mais freqüentes destes sistemas, enfatizam os relatos de violência intrafamiliar, tais como: abuso emocional, físico e sexual, além da negligência e do abandono (De Antoni, Mesquita \& Koller, 1998; Farinatti, 1997). Estudo recente realizado em Porto Alegre demonstra que oitenta por cento dos casos de violência denunciados ocorreram dentro da casa da vítima, sendo que os perpetradores da agressão eram, principalmente, pais biológicos ou adotivos (AMENCAR, 1999). Um estudo baseado em expedientes ajuizados nas coordenadorias das promotorias da infância e adolescência dos casos de abuso sexual é ainda mais alarmante, pois demonstra que em noventa por cento dos casos o agressor ocupa a função paterna na família (Azevedo, Kreisner, Machado, Martins \& Koller, no prelo).

A violência intrafamiliar não é, na maioria dos casos, claramente identificável (Farinatti, Biazus \& Leite, 1993). Origina-se de relações interpessoais assimétricas e hierárquicas, marcadas por desigualdade e subordinação (Koller, 1999). Pode ser fruto de uma crise não resolvida na família, ou pode ser um padrão de relacionamento que acompanha a história familiar daquele grupo. A ocorrência de violência intrafamiliar pode ser ocultada como um segredo, o que revela a coesão doentia deste grupo. $\mathrm{O}$ ingresso na adolescência, que se evidencia pela transformação emocional e cognitiva, pode tornar, no entanto, o(a) jovem mais capaz de enfrentar e desvelar a situação de violência e, assim, buscar recursos diferenciados para amenizar ou resolver esta situação. Estes adolescentes podem denunciar o agressor, defenderse dele ou saírem de casa (De Antoni \& Koller, 2000a; Fahlberg, 1996).

O Estatuto da Criança e do Adolescente (ECA, Lei n. $\left.{ }^{\circ} 8.069,1990\right)$ prevê a proteção integral de crianças e adolescentes, preconizando 
que não serão objeto de qualquer forma de negligência, discriminação, exploração, violência, crueldade e opressão. Com base no ECA, foram criados mecanismos sociais de proteção para aqueles que experienciam violência em seu ambiente doméstico, seja como vítimas ou como testemunhas. A identificação ou suspeita de violência exige que o caso seja denunciado ao Conselho Tutelar (Lisboa \& Koller, no prelo). No entanto, conforme enfatizam Oliveira e Flores (1999), há, em geral, inadequação entre a denúncia e a implementação de uma pretensa medida de proteção. As formas de tratamento dos casos afastam a criança ou adolescente do ambiente familiar, abrigando-os em uma instituição por um tempo determinado (Azevedo et al., no prelo; Oliveira \& Flores, 1999). A institucionalização da vítima de violência doméstica pode ser interpretada como mais uma violência ao seu desenvolvimento emocional e psicológico. Os estudos de Oliveira e Flores (1999) e Azevedo et al. (2000) revelam que, em geral, não são tomadas medidas de acompanhamento, orientação e apoio sócio-familiar e, mais ainda, que o agressor é mantido no ambiente doméstico, até que seja provada sua culpa e determinada qualquer medida legal de punição ao seu delito.

Com base nestes aspectos, este estudo visa a investigar como as adolescentes percebem sua família, bem como as suas expectativas em relação à constituição de uma família no futuro, após a vivência de violência intrafamiliar, o afastamento da família e a institucionalização.

\section{Método}

\section{Participantes}

Participaram deste estudo doze meninas de 12 a 17 anos, em dois grupos, denominados “A" e "B", abrigadas há menos de quatro meses em uma instituição governamental, por medida de proteção, após a identificação de maus tratos vivenciados no contexto familiar, tais como: abuso físico, emocional e sexual, negligência e abandono.

\section{Procedimentos}

O método para coleta de dados utilizado neste estudo foi o Grupo Focal (De Antoni, 2000; Morgan, 1997). O Grupo Focal é utilizado em 
pesquisas qualitativas com o objetivo de investigar a visão dos participantes em relação a uma experiência ou evento através da interação grupal. Foram realizados dois grupos focais com seis adolescentes cada (Grupo Focal “A” e Grupo Focal “B”). A moderação dos grupos foi realizada pela primeira autora, com o apoio logístico de duas auxiliares de pesquisa. A execução do grupo foi estruturada em planejamento prévio e contemplou as seguintes etapas em cada uma das três sessões:

(1) Rapport: para amenizar a ansiedade inicial do grupo, fazer um contrato inicial para a realização das diferentes etapas e enfatizar as combinações gerais, tais como: horário, sigilo das informações, respeito com as opiniões surgidas, etc.;

(2) Técnica de dinâmica de grupo: para favorecer a descontração e, ao mesmo tempo, introduzir o tema "família". Em umas das sessões, por exemplo, a moderadora iniciou a frase: "Era uma vez uma família..." e propôs a tarefa de formar uma história a partir deste estímulo para o grupo. A continuidade da tarefa implicava associar a história às próprias vivências do grupo.

(3) Discussão: foram propostas questões de orientação previamente elaboradas para manter a discussão do grupo no tema pesquisado. As principais questões foram: O que é uma família? Quem faz parte de uma família? Quais são as principais funções da sua família? Quais são as principais funções do seu pai, da sua mãe, dos seus irmãos e as suas? Como você vê sua família no passado? Como você vê sua família atualmente? O que você espera de uma família? Como será sua família no futuro?

(4) Avaliação: no término da sessão foi falado sobre os sentimentos surgidos frente ao tema. Nesta etapa, a moderadora escutou as adolescentes, certificando-se que se sentiam bem para deixar o grupo.

Os grupos foram realizados na instituição. Cada sessão teve a duração de aproximadamente uma hora e trinta minutos, e aconteceram em três turnos sucessivos. As sessões foram gravadas e transcritas posteriormente. O Grupo Focal "A" caracterizou-se por um comportamento dispersivo e irônico, manifestado pela necessidade de desviar do tema proposto e por risos constantes, além da necessidade 
de reafirmar o sigilo das informações. Apresentou diálogos marcados por frases curtas e criativas. O Grupo Focal "B" caracterizou-se por um comportamento reflexivo e pela manifestação de um sentimento de culpa sobre sua situação. Houve situações de choro e de tristeza e o tema foi abordado, em vários momentos, através de monólogos ou frases longas.

\section{Resultados e Discussão}

As verbalizações dos grupos focais foram analisadas através de Análise de Conteúdo (Bardin, 1977). Foi adotado o critério semântico para a identificação de categorias temáticas, baseadas nos "núcleos de sentido", que compunham a fala do grupo e cuja presença podem ter algum significado para o objetivo analítico escolhido. Os grupos focais foram analisados e discutidos separadamente, pois são compreendidos como contextos únicos e diferentes.

\section{Família na Visão do Grupo Focal "A"}

Foram identificadas três categorias: a) Configuração Familiar, b) Papéis Familiares e, c) Inter-relações Familiares, que serão discutidas a seguir, juntamente com os exemplos das falas das adolescentes.

A discussão das categorias identificadas no Grupo Focal "A" centrou-se nas relações familiares experienciadas por estas adolescentes. A Configuração Familiar foi representada pelas pessoas que as adolescentes consideram como membros da sua família, isto é, composta por pessoas pelas quais nutrem sentimentos afetivos. Portanto, a configuração está vinculada mais ao sentimento de amor do que ao laço consangüíneo. Foram citados como pertencentes à família: os pais biológicos e/ou adotivos, padrastos, irmãos, tios, avós, primos, madrinhas, amigos e outras pessoas que as auxiliaram em determinado período de suas vidas. As adolescentes enfatizaram que: "Família é estar com pessoas que nós amamos realmente. Não importa se é do nosso próprio sangue" (Alice ${ }^{2}$ ). As meninas consideram que não fazem parte da família aquelas pessoas que, embora tenham algum tipo ou grau de parentesco, não participaram da sua criação ou não contribuíram para o seu bem estar. O padrasto, o pai ou a mãe biológi- 
cos foram citados como exemplos dessa condição. O laço de consangüinidade não é valorizado por essas adolescentes, como neste exemplo: “...não adianta colocar no mundo e não dar colo, enquanto que uma pessoa que não é do meu sangue me deu carinho, que nem a minha mãe adotiva. Então, logicamente, eu vou escolher aquela pessoa. A gente não pode escolher, mas pode considerar" (Alice). Portanto, estas adolescentes valorizam as formas de interação com base nas relações de amizade, em que prevalecem a afinidade e a responsabilidade sobre o cuidado entre os membros que compõem a família, isto é, a criação. O grupo enfatizou que "criar é dar amor".

Estas visões, relatadas pelas adolescentes, revelam a compreensão do microssistema familiar conforme a definição de família, sugerida pela perspectiva ecológica (Bronfenbrenner, 1979/1996, 1986) e psicológica (Laing, 1983). A família é vista, portanto, em um ambiente no qual existe uma configuração de seus membros marcada por relações de proximidade, reciprocidade, estabilidade e afeto. A família é constituída por pessoas significativas com as quais possuem relação de apoio e de troca. Sendo assim, a visão do Grupo Focal "A" sobre a configuração familiar demonstra que a sua constituição está relacionada à qualidade da relação estabelecida entre as pessoas que são consideradas como membros da família e não, necessariamente, aos laços consangüíneos.

A categoria Papéis Familiares está relacionada às expectativas em relação ao desempenho de tarefas e atividades específicas de cada familiar. Na visão das participantes do grupo "A", os papéis do pai e da mãe são igualitários quanto às atribuições ou funções: "a função da mãe é a mesma do que o do pai” (Aline). Para estas meninas, não há distinção entre as funções parentais, sendo relacionadas à "criação", "cuidado", "afeto", "acolhida", "apoio", "ensino" e "atenção”. Esta semelhança nas atribuições, em que os papéis parentais estão mais igualitários, foi justificada, na literatura, pelas mudanças sociais ocorridas nas últimas décadas, isto é, pela disputa da mulher no mercado de trabalho, participação tanto no sustento como na organização cotidiana da casa, resultando dupla jornada, além do declínio da autoridade paterna (Badinter, 1980; Fonseca, 1995). No entanto, segundo 
Zamberlan, Camargo e Biasoli-Alves (1997), ainda persiste uma certa distinção entre os papéis do pai e o da mãe na "família nuclear" (p. 39), isto é, formada pelos pais e seus filhos dependentes. O papel assumido pela mãe está relacionado à criação e ao cuidado dos filhos, afeição, proteção, orientação e estimulação. O papel do pai, além de prover o sustento (juntamente com a mãe), envolve administrar tarefas e rotinas que se traduzem em disciplina, valores morais, educativos e de autoridade. A visão do Grupo Focal “A”, que estabelece uma igualdade nas atribuições dos papéis do pai e da mãe, é diferente do descrito pelas autoras citadas, pois os mesmos não estão tão bem definidos para estas meninas. Provavelmente, isto ocorre pela forma diferenciada de configurar a família, isto é, não seguindo o padrão conhecido de modelo de família nuclear, como mencionam Zamberlan, Camargo e Biasoli-Alves (1997).

No entanto, algumas meninas verbalizaram haver uma diferença na forma com que os pais interagem com os filhos. A mãe é mais incisiva ao impor limites e ao cobrar comportamentos e atitudes e o pai aparece como mais carinhoso e paciente em alguns casos, como neste exemplo:

Alice - "O pai é um pouco mais carinhoso. Um pouco mais carinhoso do que a mãe. Quando a gente tem dificuldades ele é mais carinhoso, claro, nem todos. A mãe já briga, já dá bronca, já xinga.

Aline - O pai sabe mais conversar, a mãe também sabe, só que o pai tem mais jeito.

Alice - Ainda mais quando a filha é mulher.

Aline - Ele te ouve, te aceita. Mãe já é mais...não quer que a gente saia. Adriana - Humm...Não quer que a gente use saia!

Alice - Tem vergonha da cara da gente!

Aline - É mais família. O pai senta do meu lado para conversar Adriana - Eu não acho que o meu pai seja assim Andréa - Nem eu!"

Para o Grupo Focal "A”, o relacionamento com a mãe é mais conflituoso, pois a mesma realiza cobranças em relação aos comportamentos das adolescentes, não confia e coloca limites: "não quer que saia... não quer que use saia". O pai aparece, para algumas meninas, 
como uma pessoa que conversa, fornece conselhos e orienta: "Um pai é bom a qualquer hora" (Aline). Todavia, nas relações cotidianas em suas famílias (com as quais residiam anteriormente à instituição), a mãe estava fisicamente mais presente no lar do que o pai. Das seis meninas, cinco residiam com a mãe biológica e uma, com a adotiva. Em relação ao pai, das seis meninas, cinco não têm contato ou têm contato superficial com o pai biológico (separação, morte, desaparecimento). A única que vive com o pai biológico não tem boa relação com ele. O padrasto foi o agressor no caso de duas meninas e apenas duas possuem padrastos que consideram como um pai, mas não estavam convivendo, antes da institucionalização, com os mesmos.

Evidencia-se, então, um desgaste emocional na relação com a mãe e uma idealização, por parte das meninas, da relação com seu pai. O desgaste na relação com a mãe, uma das pessoas que deveria estar mais próxima em sua rede de apoio social e afetivo, coloca a menina numa situação de vulnerabilidade, isto é, a mãe, que poderia desempenhar o papel de cuidadora, não o faz. Além disso, esse desgaste promove a falta de confiança e é desencadeado por ela, levando, conseqüentemente, à falta de diálogo e ao abuso emocional (agressões verbais) e físico (De Antoni, 2000; De Antoni \& Koller, 2000b). Em relação ao pai, observa-se que esta ausência do lar torna a figura paterna idealizada. $\mathrm{O}$ afastamento físico e emocional distancia o pai dos problemas cotidianos da família. E, de certa forma, auxilia a preservar uma imagem de um pai compreensivo, amoroso, que a "aceita" como ela é e que poderia "salvá-la" da situação atual. Esta forma de perceber o pai pode desencadear uma situação de risco, pois a menina poderá depositar expectativas de uma interação com o mesmo que somente existe na esfera do ideal. No passado, o pai foi o agressor ou esteve ausente e, assim, não a protegeu do abuso. Atualmente, a realidade é que o pai não está presente para auxiliá-la. É provável que a menina idealize a figura paterna para evitar o sofrimento causado pela realidade de abandono que vive em função da institucionalização, e para nutrir um sentimento de esperança de que alguém a ama e que poderá modificar sua situação e sua vida. No entanto, o que ocorre na realidade é que os pais não as protegem e as colocam em risco ao contribuir para o estabelecimento da situação de institucionalização. 
Os papéis de irmã e de filha aparecem mais delineados na fala das adolescentes. Isto pode estar relacionado à questão da adolescente vivenciar estes papéis no seu microssistema familiar. As meninas sugerem que o papel do irmão mais velho é de cuidado e proteção em relação aos irmãos menores. A amizade é a base da relação com os seus irmãos mais velhos, porém, aparece certa dificuldade em estabelecer diálogo com os seus irmãos menores, quando estes são crianças, pois os interesses são diferentes. Há uma relação de poder dos irmãos mais velhos sobre os mais novos, que pode levar a situações de brigas ou de submissão. Essa afirmação pode ser constatada no seguinte diálogo:

Andréa - "Eu acho que o meu papel de irmã mais velha e de irmã do meu irmão mais velho é não deixar eles entrarem nas drogas e nem no álcool, é a pior coisa que tem.(...)

Moderadora - Os irmãos mais velhos têm diferença dos mais novos? Aline - Têm. Só porque são mais velhos acham que têm o direito de mandar na gente. Querem dar ordens. Como a minha irmã. A gente se pegou a tapas. Agora ficou ruim, não quero voltar a ser amiga dela.

Alice - A minha irmãzinha, ela é mais nova. Eu não falo com ela até hoje. Ela tem quatorze e quer mandar em uma de dezessete."

A relação de poder estabelecida entre os irmãos é percebida no controle, cuidado e comando que os irmãos mais velhos exercem sobre os mais novos. Porém, observa-se que é um "pseudo poder". O termo "pseudo poder" está sendo utilizado neste estudo para expressar a idéia de que há hierarquia que privilegia a ordem de nascimento e que deve ser respeitada. No entanto, existe apenas a idéia deste poder, pois o mesmo não se concretiza nas situações cotidianas que envolvem as relações entre os irmãos. Além disso, o grupo "A” reporta essa idéia para si em relação aos seus irmãos menores e, assim, apresenta um sentimento de indignação frente ao comportamento de confronto do irmão mais novo às suas ordens. No que se refere à sua relação com os seus irmãos mais velhos, as meninas repetem o mesmo comportamento dos irmãos mais novos, ao não aceitarem as ordens impostas: "os irmãos mais velhos acham que têm o direito de mandar na gente, querem dar ordens" (Aline). Esta idéia de poder do irmão 
mais velho sobre os irmãos mais novos pertence ao macrossistema e influencia os demais contextos, principalmente o microssistema familiar. A relação com base no "pseudo poder", no momento em que é repudiado ou compelido pelos irmãos, pode desencadear conflitos e comportamentos abusivos de ambas as partes, tais como: a agressão e a rejeição (quando a ordem não é cumprida) e a submissão (quando a ordem é cumprida sob coerção).

Esta visão de que existe uma supremacia do filho mais velho da prole ocorre historicamente, segundo Ariès (1973/1981), desde o século XIII. O protecionismo sobre o filho mais velho visava evitar a perda do patrimônio e a manutenção da linhagem. Observa-se os resquícios desta concepção no macrossistema dessas adolescentes. Por outro lado, de acordo com Zamberlan, Camargo e Biasoli-Alves (1997), o monitoramento das crianças por seus irmãos mais velhos é um dos aspectos que compõem uma nova ordem das relações sociais, justamente pela necessidade da mulher buscar o sustento da família fora do ambiente doméstico.

A relação de amizade entre os irmãos aparece quando as meninas identificam no papel do irmão mais velho aspectos de cooperação e proteção favoráveis à interação, como o de "ajudar, ser amigo, não deixar entrar nas drogas e no mundo do álcool" (Andréa). Parece que os irmãos mais velhos tendem a repetir o modelo dos papéis "tradicionais" esperados de pai e de mãe, que estão relacionados à proteção, orientação, criação, cuidado e autoridade descritos por Zamberlan, Camargo e Biasoli-Alves (1997, p. 42).

Parece que tanto a relação de amizade como a de "pseudo poder" estão baseadas na necessidade de resgatar uma figura que represente autoridade. Steinberg (1996) constatou que os pais de adolescentes, vistos como autoridade, auxiliam no desenvolvimento da autonomia com responsabilidade, ao conversar sobre a importância da disciplina. Pais autoritários, ao contrário, mantêm a dependência e a submissão do filho ao exigirem que o mesmo obedeça às ordens sem questionar. Para estas adolescentes, a relação com base na amizade entre irmãos permite às meninas terem uma visão do irmão mais velho como autoridade, e assim ter uma maior aproximação afetiva, de apoio e de 
limites necessários para afirmar o senso de estabilidade e de permanência do microssistema familiar. Por outro lado, na relação de "pseudo poder" entre os irmãos, as meninas podem confundir o comportamento autoritário como uma manifestação de autoridade e, assim, não se dar conta da ocorrência do abuso. Observe-se o exemplo seguinte:

Ana - "O meu irmão de sete anos, eu fazia assim: João vai ali e dobra as roupas. E agora mana? Vai lá e varre o pátio. E eu sentada. E agora, mana? Tu pegas aquele cobertor ali e estende na cama. E depois? Agora vai para a pia lavar a louça. Como eu explorava o coitadinho. Ele ficava olhando e dizia: Mana, o que mais? Ele só fazia assim. E eu ficava sentada olhando para a cara dele.

Adriana - E ele não dizia: Não!

Ana - Ele fazia com tanta vontade que dava pena".

Em relação ao seu papel na família, as adolescentes o relacionam às tarefas domésticas, como cozinhar, lavar roupas, limpar a casa, ou com o papel de cuidador, por exemplo, das crianças menores, da mãe doente ou da avó. Além da possibilidade de trocar afeto, isto é, amar e ser amada.

Moderadora - "Qual a função de vocês na família?

Alê - Nossa? É fazer comida.

Andréa -Lavar roupa.

Aline - Ajudar.

Alê - Limpar os nenês.

Aline - Lavar roupa, lavar louça.

Alice - Esquentar a barriga no fogão e esfriar no tanque... e amar e ser amada."

Na visão destas adolescentes, elas, no papel de filhas, desempenham o papel descrito na literatura como o assumido pela mãe em uma família nuclear (Zamberlan, Camargo \& Biasoli-Alves, 1997, p. 39). Embora tenham ocorrido mudanças importantes nas últimas décadas em relação à divisão e ao compartilhamento das atividades desempenhadas no contexto familiar, as atribuições descritas por estas meninas estão social e culturalmente estabelecidas em nossa sociedade. Na dimensão do macrossistema, encontra-se o estereótipo que envol- 
ve a divisão do trabalho dentro do ambiente doméstico de acordo com o sexo da pessoa (Spina, Morita, Camargo \& Cerveny, 1979; Zamberlan, Camargo \& Biasoli-Alves, 1997). Na pesquisa sobre escolhas profissionais, Bonamigo e Koller (1995) constataram que as expectativas dos adolescentes, pertencentes ao nível sócio-econômico baixo, estão relacionadas ao desempenho de atividades diferenciadas entre os sexos. As mulheres cuidam da casa e dos filhos e os homens trabalham "fora" visando ao sustento da família. Na dimensão do microssistema familiar, as atividades descritas pelas meninas estão relacionadas a este estereótipo da divisão do trabalho pelo sexo e estão de acordo com o padrão de comportamento esperado e incentivado pelos próprios membros da família. Portanto, há uma conformidade das meninas em relação ao tipo de atividades desempenhadas no microssistema familiar.

No momento em que estas meninas assumem as atividades socialmente atribuídas ao gênero feminino e associadas ao papel de mãe, elas passam a ter um papel importante na família. Ao desempenhar as tarefas domésticas, parece que a menina se sente pertencendo ao microssistema familiar e, assim, acredita que há um vínculo afetivo subjacente, como mostra esta frase: "esquentar a barriga na fogão e esfriar no tanque...amar e ser amada". Este sentimento pode ser intensificado pela necessidade que os membros de uma família possuem de manter o senso de permanência no grupo familiar, através da execução das tarefas rotineiras, e o senso de estabilidade, através da relação afetiva estabelecida (De Antoni, Medeiros, Hoppe \& Koller,1999).

Ao mesmo tempo, ao assumirem este papel, as meninas encontram dificuldades de mostrar à sua família que também necessitam ser cuidadas e protegidas. Sendo assim, parece que há um empobrecimento das relações familiares, pela rigidez nas atribuições e no comportamento, que são depositados no seu papel. Esta rigidez as impede de efetivarem uma maior quantidade e qualidade de trocas e de papéis no ambiente familiar e em outros ambientes. Por exemplo, as adolescentes excluíram do seu papel de filha outras atividades inerentes e importantes para esta fase de desenvolvimento, como estudar, sair com amigos, divertir-se, etc., e outros contextos que compõem o seu mesossistema, como a escola, igreja, amigos. 
$\mathrm{Na}$ categoria Inter-relações Familiares as adolescentes descrevem, a princípio, a família como um grupo de pessoas que se relacionam de forma unida e feliz, sendo que as inter-relações familiares deveriam ser estabelecidas pela ajuda. Porém, com a discussão do tema, as meninas se dão conta que as suas famílias são repletas de problemas e desavenças: "É, vamos ver as famílias aí e deixar os problemas. Vamos deixar os problemas e falar de outros problemas" (Alê). Portanto, aquela idéia inicial é logo substituída por uma visão que está de acordo com a realidade das suas inter-relações familiares. E, ao falarem sobre as suas famílias, constataram somente a presença da violência. No entanto, o grupo "A" compreende esta forma de relacionamento como inerente ao contexto familiar, pois "apanhar é normal"(Adriana), "família que não tem briga não é família" (Alice), entre outros exemplos. Portanto, as inter-relações no microssistema familiar dessas meninas se estabelecem na presença de aspectos que envolvem risco e podem tornar a família ou seus membros vulneráveis a comportamentos indesejados, por exemplo:

Adriana - "A gente não vive só do lazer. Olha ali, oh! União, amor, afeto...

Alice - O que mais falta na minha casa!

Adriana - Diálogo...Um monte de bagulho. É, não tem quase nas casas. O que mais tem é drogas, medo, falta de respeito, violência."

Ao concluir a discussão a respeito da percepção do Grupo Focal "A" sobre família, observa-se que essas meninas buscam, nas pessoas que elegem como pertencentes ao grupo familiar, o apoio emocional necessário para enfrentar as situações de "stress". Esta forma de configurar a família pode agir como proteção, pois permite ampliar a rede de apoio pertencente ao microssistema familiar, indo além do grau de parentesco. Do mesmo modo, o papel de irmã desempenhado por estas adolescentes pode atuar de forma protetora, isto é, inibindo a atuação dos indicadores de riscos, quando estiver relacionado à amizade e à cooperação nas relações com os irmãos, assim como o papel de filha, quando se relaciona à estruturação de determinadas atividades domésticas que visem o bem-estar da família. 
Hawley e DeHaan (1996) afirmaram que, freqüentemente, a família colabora como fator de proteção para a resiliência individual. Resiliência é a capacidade de enfrentar situações ou eventos causadores de "stress" de forma satisfatória (Rutter, 1987). Os indicadores de proteção para a família, de acordo com Hawley e DeHaan (1996) são: o afeto, a coesão e a estabilidade. Os aspectos identificados na fala do grupo podem promover a resiliência nestas meninas e em suas famílias, pois possibilitam a manutenção das relações familiares através do apoio percebido, do senso de permanência e de estabilidade e da coesão. Portanto, estes aspectos favorecem à família agir de forma protetora diante das situações geradoras de "stress" para essas adolescentes.

Por outro lado, a visão destas meninas sobre suas famílias evidencia a existência de indicadores de risco severos. Foram identificados como risco para o desenvolvimento saudável da adolescente e de sua família: os papéis dos pais com atribuições igualitárias, ambos têm as mesmas atribuições de cuidado e de criação, porém, na realidade dessas meninas, nenhum dos dois assume este papel de forma efetiva; a idealização da figura paterna e o desgaste da relação com a mãe; a relação de "pseudo poder" entre irmãos, que leva a atitudes autoritárias; a atribuição do papel de filha voltado para atividades tradicionalmente desempenhadas pela mãe e, como conseqüência, uma rigidez que a impede de desempenhar outros papéis em outros contextos. Esses indicadores de risco, identificados de acordo com a percepção do grupo, são prejudiciais no estabelecimento de uma relação familiar capaz de apoiá-la de forma consistente e efetiva nas situações adversas e causadoras de stress, como a violência doméstica. Este fato pode ser comprovado pela situação de institucionalização na qual a menina vive atualmente.

Nas expectativas de futuro destas adolescentes, foi identificada a capacidade de realizar planos com base na esperança que haja melhoria da qualidade de sua vida e de sua família, como exemplifica esta fala: "quero que minha família seja feliz" (Alê). As expectativas de futuro remoto, isto é, em sua vida adulta familiar, apontam para a constituição de uma família. Há expectativa em um relacionamento amoroso, em que as características do parceiro envolvam atributos físicos, como 
beleza; morais, como sinceridade e fidelidade; e emocionais, como ser carinhoso. Não casar também aparece como resposta. O casamento pode ou não gerar filhos. Porém, o grupo "A" enfatizou a questão de não repetir nos filhos os maus tratos experienciados por elas, como no exemplo a seguir:

Aline - "Tá tia, eu falo. O meu sonho ... Ah, guria pára de rir (fala para Ana) O meu sonho é casar, ter um filho ou dois, mais não. Ter a minha casa, não aqui, né, aqui onde eu moro não, bem longe. Uma casa bonita, grande. Um namorado bonito, fiel... amoroso, bem maior que eu, bem mais velho...Eu quero que seja feliz, né, meus filhos. Não quero que eles passem o que eu estou passando hoje e o que eu passei. (risos)

Alê - Não quero passar para os meus filhos o que eu passei é ótimo! (rindo)

Aline - Sim, o sofrimento.

Alê - Então fala: 'Não quero que os meus filhos passem o que eu passei' (risos)."

Houve uma resposta relacionada à falta de expectativas no futuro. Este fato revela a falta de perspectivas e planejamento sobre a sua vida: "Eu não tenho sonho, eu não espero nada do futuro, eu não sei o que vem pela frente..." (Andréa).

A constituição de uma família de procriação está, em geral, definida e planejada. Os filhos serão oriundos de um relacionamento amoroso e duradouro, e esta visão sobre a relação fornece indícios de que o modelo de família, como instituição sólida e saudável, persiste na visão das meninas, apesar da situação de violência experienciada neste contexto. Este fato pode ser indicador de proteção ao favorecer a adolescente a repensar sobre a disciplina a ser adotada na criação dos filhos e o apoio fornecido através do "amor, carinho e atenção". Esta é uma perspectiva diferenciada da criação que recebe dos seus pais. As meninas possuem a idéia de não repetir a forma de relação com base nos maus tratos. Segundo Koller (1999), a consciência sobre a história de violência vivida por seus antecedentes poderá ser um indicador de proteção, pois poderá evitar os maus tratos. E, assim, poderá proporcionar o rompimento do ciclo da transmissão intergeracional da violência (Belsky, 1993). 
A escolha do parceiro é evidenciada pelas expectativas idealizadas tipicamente pelas meninas na fase da adolescência, como ser bonito, amoroso e fiel. Apareceu no Grupo Focal "A", de forma irônica, o desejo de que o parceiro seja um homem mais velho, para fornecer estabilidade econômica e certo conforto:

Ana - "Não, eu quero casar com 22 e ter um marido mais velho para me sustentar.

Andréa - Tia, quando eu casar eu não vou trabalhar, meu marido vai ter que me dar de tudo!

Foi identificado, também, um sentimento que as adolescentes denominaram de "sonho", isto é, um desejo difícil de se realizar em sua(s) vida(s), mas possível no imaginário, como: "Eu queria casar, ter o Fábio Assunção casado comigo. Ui, meu Deus, que homem!” (Andréa). Este comportamento pode ser compreendido como pertencente à fase da adolescência, em que há necessidade de buscar uma visão mais realista dos fatos e, ao mesmo tempo, há necessidade de sonhar e criar ídolos com os quais possam se identificar e auxiliar na formação de sua identidade (Erikson, 1976; Hill, 1980).

Os comentários do Grupo Focal "A", sobre suas expectativas de futuro, revelam a possibilidade de constituição de novas famílias com perspectiva de estabelecerem-se relações familiares diferentes das experienciadas, estruturando seu microssistema familiar com interações e inter-relações mais duradouras, amorosas e abertas. Estas expectativas podem ser compreendidas como uma necessidade e um desejo de constituírem uma família resiliente e, assim, romper com a violência e os maus tratos. Portanto, é uma visão salutar dessas adolescentes almejar uma qualidade de vida melhor.

\section{Família na Visão do Grupo Focal "B”}

A família foi identificada através de três categorias: 1) Configuração Familiar, 2) Papéis Familiares, e 3) Inter-relações Familiares, que serão discutidas a seguir, juntamente com os exemplos extraídos das falas das adolescentes. 
Para o Grupo Focal “B”, a categoria Configuração Familiar está representada pelas pessoas que compõem a família. Estas adolescentes confirmaram a presença dos pais, irmãos, filha, tios, avós, isto é, pessoas com as quais possuem algum grau de parentesco, com base em laços consangüíneos. O grupo discutiu a respeito de um casal formar uma família, pois algumas meninas compreendem que a presença de filhos é importante para se configurar uma família, enquanto outras acreditam que a família se constitui a partir de um casal. Como demonstra o exemplo a seguir:

Bruna- "Bom, sei lá, eu acho que eu não considero uma família ...é um casal. Moderadora - E o que tu consideras uma família?

Bruna - Ah... uma família tem mãe, pai, irmãos, essas coisas.

Moderadora - Gurias, concordam com a Bruna?

Bete - Eu não sei, eu acho que é, porque eu acho assim, que uma família começa com um casal, é isso que eu considero.”

Na visão destas adolescentes, a família configura-se apenas por pessoas que possuem algum grau de parentesco, sendo que o laço consangüíneo é um fator importante na identificação da família. Além disso, para o Grupo Focal "B", a presença de pelo menos um dos pais e a existência de uma relação hierárquica deles sobre seus filhos apontam para a delimitação da constituição de uma família. Berenstein (1988) e Szymanski (1997) definem o modelo idealizado de família como aquele baseado no parentesco, ou seja, a família nuclear burguesa, em que a estrutura predominante é composta pelo pai, a mãe e os filhos. Portanto, parece que estas adolescentes apresentam uma visão de acordo com um modelo idealizado e valorizado pelo macrossistema e, assim, restringem o seu microssistema familiar àquelas pessoas com grau de parentesco. Outras pessoas que poderiam ser incluídas, pela afetividade e apoio emocional, não são citadas como membros da família. Esta forma de configurar a família pode ser compreendida como um risco para essas meninas, pois o modelo idealizado não corresponde à realidade. Das seis participantes do grupo, cinco residiam anteriormente com pais substitutos ou cuidadores e apenas uma residia com os pais biológicos e irmãos. 
A categoria Papéis Familiares abrangeu as atribuições, as funções e as expectativas sobre o desempenho de cada participante da família, isto é, da mãe, do pai, dos irmãos, de filha e o da própria família. Os papéis do pai e da mãe foram identificados de forma distinta. $\mathrm{O}$ papel da mãe está relacionado ao apoio (“dar força", "consolar”), ao afeto (carinho e amor) e à educação. Envolve estar presente em todos os momentos, participando da vida da filha:

Bete - "Acho que mãe representa tudo, sabe, quer dizer, mãe é para todas as horas e momentos, se eu pudesse ter minha mãe do meu lado! Moderadora - qual é a função da mãe ?

Bruna - Dar amor, carinho.

Bianca - Pra consolar.

Bruna - Claro que talvez elas foram feitas para isso, mas não são todas, né.

Bete - ...Acho que mãe é pra isso, pra educar, pra todos os momentos. (...)

Betina - Pra quando a gente precisa, pra quando a gente não precisa, pra sempre tá ali,_aconselhando, dizendo coisas boas, o que é bom, o que é ruim, acho que só, mãe é mãe".

Em contraponto, o papel do pai está relacionado à autoridade, "dar respeito", trabalhar, sustentar a casa e colocar os limites que a mãe não consegue, como demonstra este exemplo: "O pai faz o papel dele, como as gurias disseram, pai mais é pra trabalhar, pra colocar as coisas pra dentro de casa e dar educação mesmo, não deixar fazer o que a gente quer, fazer tudo o que dá na cabeça, não deixam, eles são mais rígidos com a gente" (Betina).

Portanto, para estas meninas, o papel da mãe é o de fornecer apoio, afeto e educação diária, e o do pai é de sustentar financeiramente a casa e de transmitir autoridade ao impor limites. Zamberlan, Camargo e Biasoli-Alves (1997) descrevem esses papéis como pertencentes à família nuclear. A mesma definição dos papéis dos pais ocorreu com adolescentes pesquisados por Wagner e Bandeira (1996, p. 118), que residiam com suas "famílias originais", isto é, com o pai, a mãe e os irmãos. Esse modelo de percepção sobre a família também é comentado por Szymanski (1997, p. 26) como o "modelo de família 
nuclear burguesa com conotação normativa", em que existe um modelo pai-mãe e filhos estáveis desta relação, dentro de uma ordem e estrutura estabelecida num contexto de autoridade patriarcal. Porém, para Szymanski, ele advém de um "discurso oficial" (p. 25), imposto pelo discurso das instituições, da mídia e dos próprios profissionais que elegem uma determinada forma de interação familiar como a ideal.

A definição dos papéis dos pais descritos por estas adolescentes pode estar representando um discurso sobre os papéis sociais idealizados e valorizados pelo macrossistema destas meninas. O papel de mãe, por exemplo, é identificado pelo discurso: "mãe é mãe" ou "mãe é para dar amor, carinho, pra consolar". Ao mesmo tempo, o grupo se dá conta de que, no seu microssistema familiar, os papéis desempenhados por seus pais são diferentes desse discurso, apesar de identificar estes papéis parentais de forma idealizada. Uma menina acrescenta “....talvez elas (mães) foram feitas para isso, mas não são todas, né?". Sendo assim, a mãe, por exemplo, também pode ser vista como uma pessoa que comete erros e que inspira sentimentos desagradáveis em função dos maus tratos: "a minha mãe para mim é um bicho (...) eu odeio minha mãe, o que ela me fez" (Bianca). No entanto, aparece uma necessidade de que este papel exista, e, então, elegem no seu microssistema familiar outras pessoas para assumi-los, como a irmã ou a tia: "É como a minha segunda mãe (irmã)" (Betina) ou "A minha tia estava fazendo parte da minha vida, me ensinando o que era certo" (Bianca).

O papel social da figura paterna, para estas meninas, está relacionado à sustentação da casa e à imposição de limites, isto é, "pai serve para não deixar fazer o que a gente quer" (Betina). Porém, cinco das seis meninas do grupo não conhecem o pai ou têm pai desaparecido. A única menina que residia com o pai também relata o distanciamento físico e emocional: "meu pai trabalha de noite e eu sou muito de ficar na rua" (Betina). Szymanski (1992) abordou a questão da participação dos homens nas famílias de nível sócio-econômico baixo. As famílias são constituídas sem a presença do pai, ocasionada pelo abandono ou separação. Evidencia-se a dificuldade em estabelecer novas regras e se adaptar a esta nova realidade, pois persiste a idéia do modelo do 
homem como provedor financeiro e de autoridade. Fonseca (1995) acrescentou que a identidade paterna é assegurada, para a família, através da presença de tios e avós paternos na vida da criança. Portanto, a ausência física do pai não implica sua ausência simbólica. Parece que estas adolescentes têm a visão do papel do pai de acordo com o papel social idealizado pelo macrossistema. Assim, apresentam certa dificuldade em perceber o distanciamento entre o ideal e sua realidade. Este fato pode ser compreendido como um indicador de risco, à medida em que não permite que estas meninas articulem outras formas de estruturação familiar, pois a configuração eleita para a família não permite que outras pessoas assumam o papel de autoridade, diante da ausência do pai. Então, parece não existir um modelo de autoridade presente que possa mostrar os limites e manter a estabilidade e o senso de equilíbrio nas relações familiares, principalmente diante de mudanças, como na adolescência.

Este fato é comprovado pela rejeição do Grupo Focal "B" à presença da madrasta ou do padrasto na família. Portanto, eles não são vistos como figuras que possam desempenhar a função do pai ou da mãe:

Bruna - “...e eu não sou assim, não sou agressiva, mas eu não admitia ele (padrasto) tocar um dedo em mim, por causa que ele não era meu pai, sei lá, pra mim ele era um estranho, eu não conseguia olhar pra ele assim e ter a imagem de um pai, ele era um estranho, pior que um estranho até, um monstro assim.

Moderadora - Então vocês concordam que tem uma diferença entre pai e padrasto?

Betina - Eu acho assim, que um padrasto não substitui o papel de um pai, não faz o que um pai verdadeiro faz com a gente. (...) Se fosse no meu caso, na minha casa não entrava padrasto e nem uma madrasta também, nem madrasta, que piorou ainda.

O papel do irmão está relacionado à orientação sobre a vida e ao apoio emocional, como no exemplo: "Eu acho que a função do irmão ou da irmã, sempre que for mais velho, ajudar, levar para bom caminho, guiar, conversar e se for mais nova sentar e escutar a irmã mais velha" (Bete). Porém, há um distanciamento real, físico e emocional, entre os 
irmãos. Das seis meninas, cinco possuem irmãos que residem com outros familiares ou em outras localidades. O contato entre irmãos é esporádico ou inexistente. Quando existe, as relações não são boas, com exceção de uma menina do grupo que citou sua irmã como uma pessoa próxima afetivamente. Fonseca (1995) abordou a questão da circulação de crianças em famílias pobres como uma necessidade de sobrevivência. E este fato pode ser um dos motivos da separação dos irmãos, como descreve o exemplo: "É que quando a minha mãe faleceu, a minha avó pegou e separou cada um (irmãos)... e eu fiquei com o meu tio" (Beatriz). Portanto, o papel de irmão também é idealizado por essas meninas em função da realidade de afastamento entre os irmãos.

O papel da filha está centrado em retribuir e agradecer aos pais os cuidados recebidos, realizando as expectativas tradicionais dos pais, como estudar, ser obediente, entre outras. Por exemplo: "Nosso papel mesmo é, eu acho que é, fazer a nossa família feliz. Não dar desgosto que a gente dá... nosso papel é estudar, ter uma profissão boa, não se iludir com pouca coisa e, principalmente, respeitar mãe e pai” (Betina). Esse papel, segundo Szymanski (1994, p. 223), assemelha-se ao papel existente na "família pensada", no qual suas tarefas consistem em ajudar nos afazeres domésticos e estudar para ter uma vida melhor. $\mathrm{O}$ papel de filha, de acordo com a abordagem destas meninas, parece que está calcado numa idéia de submissão e de arrependimento. Portanto, o papel torna-se empobrecido, no momento em que serve para contentar os outros e, ao mesmo tempo, negligenciar os seus próprios desejos e aspirações.

O papel da família, na visão destas meninas, é de fornecer tranqüilidade: "se ela é tranqüila, o sono é tranqüilo" (Betina), sendo sua função a de proteção de seus integrantes. Blechman, McNamara e Wills (1996) afirmaram que o bem-estar do adolescente está relacionado ao fato da família fornecer apoio e acolhida. Para Hawley e DeHaan (1996), a família, freqüentemente, serve como proteção para seus membros, se alguns fatores estiverem presentes, como, por exemplo, a confrontação pró-ativa dos problemas, ou serve como risco, quando há conflitos e desavenças. Então, parece que as famílias destas meni- 
nas não exercem esta função de proteção, pois não proporcionam tranqüilidade, ao contrário, são indicadoras de risco, pois há desavenças, abusos e o abandono. Há um contraponto em relação à visão dessas meninas sobre a família. Para algumas, aparece como algo infalível, isto é, os acontecimentos intrafamiliares são justificados por si só e, portanto, não podem ser questionados, mesmo quando os seus familiares apresentam um comportamento inadequado, como neste exemplo: “...eu acho assim, que uma mãe, por mais que ela coloque o filho no lixo ou deixe o filho ali na hora, sei lá, eu acho que uma mãe vai ser sempre uma mãe" (Bete).

Para outras meninas, aparece uma visão mais centrada em sua realidade. As inter-relações familiares não são como gostariam, pois não há o desempenho dos papéis desejados. $\mathrm{O}$ sistema familiar funciona com a existência de situações de perda, abandono, afastamento e abuso. Como descreve este trecho a seguir: "Eu sei que eu sempre morei com a minha tia por causa que a minha mãe não cuidava de mim...por causa que têm mães que botam a gente no mundo, que nem minha mãe, minha mãe me botou no mundo e me abandonou....A minha mãe pra mim é um bicho, porque ela vira um bicho na minha frente. Até eu falava: 'Ah, eu não gosto da minha mãe, eu odeio a minha mãe, tudo o que ela me fez"'(Bianca).

Ocorre uma dificuldade em relação à autoridade nas inter-relações familiares. A mãe não consegue colocar limites e ser uma autoridade na família. O pai assume esta tarefa, somente quando está presente no lar. Portanto, há um confronto às ordens e orientações da mãe e uma idéia de autoridade posta na figura do pai: "Por causa que, às vezes, a mãe não consegue te educar, sei lá, a minha mãe por exemplo, se ela tivesse com meu pai, eu acho que eu ia respeitar muito mais minha mãe, porque eu respondia muito pra minha mãe. Ela falava comigo, eu gritava com ela. Pai, eu acho que é para dar mais respeito, mas é claro que a mãe não vai machucar os filhos, mas acho que se meu pai estivesse aí, minha mãe ia aprender a lidar comigo, no meu caso" (Bruna).

A relação destas meninas com suas mães ou cuidadoras evidencia um confronto permanente e a refutação às ordens e orientações. $\mathrm{O}$ pai, por sua vez, é visto como detentor de autoridade, mas não está 
presente fisicamente para exercê-la. No relato da pesquisa realizada por Szymanski (1994, p. 223), a autoridade na família "pensada" é exercida pelo pai e somente na ausência do mesmo a mãe poderá assumi-la. Na família "vivida", a autoridade evidencia uma inferioridade social em relação às mulheres e às crianças. Parece, então, que estas meninas repetem um modelo idealizado ao depositarem a autoridade na figura paterna, e reforçam esta inferioridade social ao refutarem a autoridade da mãe.

Ao concluir a discussão sobre família, observa-se que a visão do Grupo Focal "B" sobre a configuração familiar é restrita à estrutura de parentesco, o que ocasiona uma rede familiar formada por poucos componentes. Este fato pode ser compreendido como risco, no momento em que a menina necessita de pessoas para apoiá-la e não as encontra.

Em relação aos papéis dos membros da família, estes são idealizados pelas meninas. No entanto, algumas delas conseguem perceber o distanciamento entre o papel ideal e o experienciado no seu contexto, principalmente em relação ao papel da mãe, e assim, elegem outra pessoa, com grau de parentesco, para assumir a educação, orientação e o apoio. As outras meninas do Grupo Focal "B" mantêm a visão idealizada e cristalizada sobre os papéis familiares. A experiência desagradável na substituição de pessoas que poderiam assumir estes papéis e a rigidez em aceitar outras pessoas no contexto familiar colaboram para a idealização dos papéis parentais, principalmente o de pai. O papel da família, por sua vez, também está idealizado.

Estas adolescentes demonstram certa dificuldade em vislumbrar o seu microssistema familiar de forma mais realista, de acordo com os papéis, atividades e inter-relações existentes no contexto familiar em que vivem. Esta percepção torna-se um obstáculo para si e para os demais membros da sua família, pois dificulta o desempenho do seu papel e evidencia um microssistema familiar vulnerável diante de novas situações e mudanças. Além disso, torna-se um obstáculo para a adequada efetivação da transição normativa destas meninas, isto é, da passagem da infância para a adolescência. Esta visão idealizada da família não permite que estas meninas enfrentem a realidade de sua 
família ser violenta e negligente. Pelo contrário, esta visão incrementa o sentimento de menos valia e de culpa sobre sua situação, por exemplo: "Eu sei que eu não fui, eu não posso dizer que eu fui uma filha rebelde, mas eu também não fui uma filha exemplar, quer dizer, tudo que eu fiz eu poderia ter feito melhor" (Bete). Esta fala evidencia distorção da realidade e deslocamento da responsabilidade dos maus tratos da família para si própria. A família então passa a ser "boa", e a menina "má". Portanto, tal visão sobre família impossibilita a estas adolescentes e suas famílias estabelecerem relações mais abertas, profundas e centradas na realidade. Ao contrário, é intensificada a distorção da realidade e a dificuldade em aceitar a situação de abandono da família.

Em relação às expectativas de futuro, a constituição familiar apareceu no Grupo Focal "B". Das seis meninas, quatro querem casar e ter filhos (um ou dois), uma não soube responder se queria ou não casar e ter filhos e uma não quer constituir uma família no futuro por "medo de sofrer". A idade para casar é em torno dos vinte anos e ter filhos somente quando tiverem condições de sustentá-los.

\footnotetext{
Moderadora - "E como é essa família?

Bruna - Começa com marido, né, depois com os filhos e assim vai indo (...) Eu queria ter dois filhos, mas não sei, não quero ter muito cedo. Moderadora - Com que idade?

Bruna - É, isso aí vai depender, se eu for atriz, sei lá, vai depender, não sei. Eu acho que tem que ter idade, mas eu quero dar de tudo para o meu filho. Eu quero estar com meu futuro construído, com uma carreira boa, pra poder dar de tudo pro meu filho. Não deixar_faltar nada. Dar confortos, estudo pra eles, tudo assim. Daí, quando eu ver que eu tenho, assim, condições, aí, daí sim eu posso pensar em filhos, mas por enquanto não.
}

Quanto às características do futuro parceiro, as meninas alegaram que o mesmo deverá ser "honesto", "fiel" e "trabalhador". Os atributos físicos não foram citados. Como no exemplo abaixo: "Ah, sei lá, nem sei, eu quero ter marido, mas têm vezes que nem sei, hoje em dia esses caras não dá para agüentar. Eu me apavoro. Eu não quero maloqueiro, não gosto, tem uns chinelos, eu tenho pavor! (Bruna). 
Há uma expectativa em relação à forma de disciplinar, de educar e de passar valores para os seus futuros filhos. As adolescentes pretendem que esta relação seja diferente da forma estabelecida por seus pais: “Ah, eu não sei, procurar mostrar o caminho, pra eles, certo. Não tocar a mão neles, porque comigo não adiantou e com meus filhos, futuramente, com certeza, não vai adiantar, porque se não quiserem obedecer eu vou dar castigo, sabe, acho que se a minha mãe me criasse com castigo, eu ia ser bem diferente (...) Quero também, mostrar o caminho certo pra eles, mostrar o valor da vida..." (Bruna).

O desejo de ter filhos está relacionado aos meios para sustentálos. Este fato demonstra uma conscientização da responsabilidade que envolve a maternidade e funciona como indicador de proteção, à medida que, segundo Farinatti, Biazus e Leite (1993), a gravidez na adolescência é um indicador de risco em potencial para o maltrato infantil. Para o Grupo Focal "B", há uma necessidade de romper com o modelo educacional praticado pelos pais. A princípio, desejam evitar utilizar o abuso físico e a punição corporal com os seus futuros filhos e adotar outras formas disciplinares como o diálogo e a punição restritiva. Portanto, essa perspectiva na alteração das práticas disciplinares poderá romper com o ciclo de violência intergeracional e auxiliar no desenvolvimento saudável dos seus filhos.

Não possuir expectativas de futuro relacionadas à constituição de uma família, como aconteceu com algumas destas adolescentes, pode estar associado a duas questões. A primeira aponta para a fase de desenvolvimento que estão atravessando, isto é, a adolescência. Segundo Erikson (1976), a adolescência é evidenciada pela busca da identidade; portanto, a adolescente sente necessidade de se identificar com modelos, para então, posteriormente, refletir e efetuar suas escolhas. A segunda questão está relacionada ao risco. A falta de expectativas no futuro pode estar associada à incapacidade da menina em superar o sofrimento ocasionado pelos maus tratos e, assim, ela evita realizar planos que a possam levá-la a mais frustrações, como no exemplo: "...mesmo porque eu tenho medo, uma coisa assim que eu morro de medo de construir uma família e perder tudo de novo" (Bete). O mesmo ocorre ao delegar o controle da sua vida a Deus, eximindo-se 
da responsabilidade sobre seus atos, ao afirmar que "só Deus sabe" (Beatriz e Bibiana) sobre o seu futuro.

Por outro lado, pode-se concluir que algumas destas meninas buscam definir as suas metas visando à melhoria na qualidade de vida. Sendo assim, a expectativa de futuro torna-se um indicador de proteção, pois as adolescentes poderão criar alternativas para superar os diversos riscos aos quais estão expostas, como a pobreza, a falta de conhecimento, a gravidez na adolescência, entre outros que as levam à vulnerabilidade individual e familiar.

Comparações entre grupos focais não são apropriadas. Porém, cabe ressaltar as semelhanças identificadas nos dois grupos. A visão das adolescentes do Grupo Focal "A" sobre a família revelam que o microssistema familiar foi compreendido em sua estrutura e função pela qualidade do vínculo estabelecido, com maior flexibilidade nos papéis e atividades. No entanto, esta forma de perceber a família é idealizada, pois as inter-relações existentes na sua família reforçaram os maus tratos e levaram-nas à institucionalização. Por sua vez, o Grupo Focal "B" revela a visão sobre o microssistema familiar nitidamente idealizado, identificado como o "modelo da família nuclear burguesa”, ocasionando assim certa rigidez nos papéis, relações e atividades. Em ambos os grupos, a realidade das inter-relações existentes em suas famílias foi identificada através dos relatos das situações cotidianas vividas, contrapondo-se à visão idealizada mencionada frente às perguntas de orientação lançadas durante o Grupo Focal. A idealização sobre a instituição família, neste caso, pode ser entendida como uma forma que as meninas encontraram de se protegerem do sofrimento advindo da confrontação com sua realidade, marcada pelo abandono e pela violência. Porém, a idealização mascara a realidade e, neste momento, pensar sobre sua realidade, de forma consciente, poderá auxiliar estas meninas a enfrentarem com maior disposição sua situação.

A elaboração de um projeto de vida possibilita às adolescentes, segundo Walsh (1996), definirem metas a serem alcançadas e irem em busca da realização dessas metas. Ao mesmo tempo, demonstrar esperança no futuro pode servir como um indicador de proteção na 
constituição de uma família (Hawley \& DeHaan, 1996). Portanto, o desejo de constituição de uma família diferente da experienciada pode favorecer a busca, no futuro, de relações familiares com maior reciprocidade, afetividade e estabilidade. Assim, estas adolescentes poderão efetuar uma mudança qualitativa em seus relacionamentos ao evitar a repetição dos comportamentos que levam à violência.

\section{Agradecimentos}

As autoras agradecem a participação dos bolsistas de Iniciação Científica e alunos voluntários do Grupo de Estudos sobre Resiliência Familiar do CEP-RUA/UFRGS. Agradecem, ainda, a Paula Lima pela confecção da Figura. Apoio CNPq.

\section{Referências}

Ariès, P. (1981). História social da criança e da família. Rio de Janeiro: Guanabara. (Original publicado em 1973)

AMENCAR. (1999). Violência doméstica. Brasília: UNICEF.

Azevedo, G. N. A., Kreisner, B. G., Machado, P. X., Martins, J. I., \& Koller, S. H. (no prelo). A trajetória das crianças e adolescentes vítimas de violência sexual: fatores de risco e proteção (1998 a 2000) [Resumo]. In Universidade Federal do Rio Grande do Sul (Org.), Resumos do Salão de Iniciação Científica da UFRGS. Porto Alegre, RS: UFRGS.

Badinter, E. (1980). Um amor conquistado: o mito do amor materno. São Paulo: Círculo do Livro.

Bardin, L. (1977). Análise de conteúdo. Lisboa: Edições 70.

Berenstein, I. (1988). Família e doença mental. São Paulo: Escuta.

Belsky, J. (1993). Etiology of child maltreatment: A developmental-ecological analysis. Psychological Bulletin, 114, 413-434.

Blechman, E. A., McNamara, G., \& Wills, T. A. (1996). Family support, coping, and competence. In E. M. Hetherington \& E. A. Blechman (Orgs.), Stress, coping, and resiliency in children and families (pp. 107-133). New Jersey: Lawrence Erlbaum.

Bonamigo, L. R., \& Koller, S. H. (1995). A influência dos papéis sexuais estereotipados no projeto de vida de adolescentes de níveis sócio-econômicos alto e baixo. Estudos de Psicologia, 12(3), 47-59.

Brito, R. C., \& Koller, S. H. (1999). Desenvolvimento humano e redes de apoio social e afetivo. In A. M. Carvalho (Org.), O mundo social da criança: natureza e cultura em ação (pp.115-126). São Paulo: Casa do Psicólogo. 
Bronfenbrenner, U. (1986). Ecology of the family as a context for human development: Research perspectives. Developmental Psychology, 22, 723 742 .

Bronfenbrenner, U. (1996). A ecologia do desenvolvimento humano: experimentos naturais e planejados. Porto Alegre: Artes Médicas. (Original publicado em 1979)

Cobb, N. (1992). Adolescence: Continuity, change, and diversity. Mountain View: Mayfield.

De Antoni, C. (2000). Vulnerabilidade e resiliência familiar na visão de adolescentes maltratadas. Dissertação de Mestrado não-publicada. Curso de PósGraduação em Psicologia do Desenvolvimento, Universidade Federal do Rio Grande do Sul. Porto Alegre, RS.

De Antoni, C., \& Koller, S. H. (2000a). O psicólogo ecológico no contexto institucional: uma experiência com meninas vítimas de violência. Manuscrito submetido para publicação na revista Psicologia: Ciência e Profissão.

De Antoni, C., \& Koller, S. H. (2000b). Vulnerabilidade e resiliência familiar: um estudo com adolescentes que sofreram maus tratos intrafamiliares. Psico, 31 (1), 39-66.

De Antoni, C., Medeiros, F., Hoppe, M. W., \& Koller, S. H. (1999). Uma família em situação de risco: resiliência e vulnerabilidade. Interfaces: Revista de Psicologia, 2, 81-85.

De Antoni, C., Mesquita, J., \& Koller, S. H. (1998). Perfil de meninas maltratadas: Levantamento de dados em uma casa de passagem [Resumo]. In Sociedade Brasileira de Psicologia do Desenvolvimento (Org.), Anais do II Congresso Psicologia do Desenvolvimento (p. 46). Gramado, RS: SBPD.

Erikson, E. (1976). Identidade, juventude e crise ( $2^{\circ}$ edição). Rio de Janeiro: Zahar.

Estatuto da Criança e do Adolescente (1990). Estatuto da Criança e do Adolescente (ECA), Lei ${ }^{\circ}$ 8.069, de 13/07/1990. Porto Alegre: CORAG.

Fahlberg, V. R. (1996). Fatores que influenciam o risco de violência doméstica ( $\left.n^{\circ} .1 / 1996\right)$. Rio de Janeiro: Publicação Interna - PUC.

Farinatti, F. A. (1997). A criança maltratada. Barbarói Revista do Departamento de Ciências Humanas e do Departamento de Psicologia/UNISC, 7, 8694.

Farinatti, F. A., Biazus, D. B., \& Leite, M. B. (1993). Pediatria social: a criança maltratada. São Paulo: Medsi.

Fonseca, C. (1995). Caminhos da adoção. São Paulo: Cortez

Garbarino, J. (1992). Children and families in the social environment ( $2^{\mathrm{a}}$ edição). New York: Aldine de Gruyter.

Gill, S., Reynolds, A. J., \& Pai, S. (1995, Março). Parent types and academic achievement of children at risk: A longituDinal study. Trabalho apresentado 
no Biennial Meeting of the Society for Research in Child Development. Indianapolis: SRCD.

Hawley, D., \& DeHaan, L. (1996). Toward a definition of family resilience: Integrating life span and family perspectives. Family Process, 35, 283-298.

Hill, J. P. (1980). Understanding early adolescence: A framework. Chapel Hill: Center for Early Adolescence.

Koller, S. H. (1999). Violência doméstica: uma visão ecológica. In AMENCAR (Org.), Violência doméstica (pp. 32-42). Brasília: UNICEF.

Laing, R. D. (1983). A política da família (2 $2^{\mathrm{a}}$ edição). São Paulo: Martins Fontes.

Lisboa, C., \& Koller, S. H. (no prelo). Questões éticas na pesquisa com crianças vítimas de violência doméstica. Aletheia, 11.

Minuchin, S. (1982). Famílias: funcionamento e tratamento. Porto Alegre: Artes Médicas.

Morgan, D. (1997). Focus groups as qualitative research. Newbury Park: Sage.

Oliveira, M. S., \& Flores, R. Z. (1999). Violência contra crianças e adolescentes na Grande Porto Alegre. Parte A: Apenas boas intenções não bastam. In AMENCAR (Org.), Violência doméstica (pp. 71-86). Brasília: UNICEF.

Rutter, M. (1987). Psychosocial resilience and protective mechanisms. Journal of Orthopsychiatry, 57, 316-331.

Spina, A., Morita, A., Camargo, C., \& Cerveny, C. (1979). Papéis familiares em famílias de periferia. Cadernos PUC, 15, 90-101.

Steinberg, L. (1996). Adolescence. New York: McGraw-Hill.

Szymanski, H. (1992). Trabalhando com famílias. Caderno de Ação, 1, 1-39.

Szymanski, H. (1994). Educação para família: Uma proposta de trabalho preventivo. Revista Brasileira de Crescimento e Desenvolvimento Humano, IV, 34-39.

Szymanski, H. (1997). Teorias e "teorias" de famílias. In M. C. B. Carvalho (Org.), A família contemporânea em debate (pp. 23-27). São Paulo: EDUC.

Wagner, A., \& Bandeira, D. R. (1996). O desenho da família: um estudo sobre adolescentes de famílias originais e reconstituídas. In R. M. Macedo (Org.), Coletâneas da ANPEPP: família e comunidade (pp.115-126). São Paulo: Press Grafic.

Walsh, F. (1996). The concept of family resilience: Crisis and challenge. Family Process, 35, 261-281.

Zamberlan, M. A. T., Camargo, F., \& Biasoli-Alves, Z. M. M. (1997). Interações na família: Revisões empíricas. In M. A. T. Zamberlan \& Z. M. M. BiasoliAlves, Interações familiares: teoria, pesquisa e subsídios à intervenção (pp. 39-57). Londrina: UEL. 
Clarissa De Antoni é psicóloga, especialista em Psicologia Social (PUCRS), mestre em Psicologia do Desenvolvimento do Curso de PósGraduação em Psicologia do Desenvolvimento da Universidade Federal do Rio Grande do Sul. Membro do Centro de Estudos Psicológicos sobre Meninos e Meninas de Rua (CEP-RUA/UFRGS), desde 1996. Coordenadora do Núcleo de Estudos sobre Desenvolvimento Comunitário e Cidadania e da Equipe de Pesquisa sobre Resiliência Familiar do CEP-RUA/UFRGS.

Sílvia Helena Koller é psicóloga, doutora em Educação, Pesquisadora do CNPq e Professora do Curso de Pós-Graduação em Psicologia do Desenvolvimento da Universidade Federal do Rio Grande do Sul. Coordenadora do Centro de Estudos Psicológicos sobre Meninos e Meninas de Rua (CEP-RUA/UFRGS). Endereço para correspondência: CEP-RUA/UFRGS, Instituto de
1 Este estudo faz parte da Dissertação de Mestrado em Psicologia do Desenvolvimento (UFRGS) da primeira autora, orientada pela segunda autora.

2 Para preservar a identidade das participantes, foram atribuídos nomes fictícios.

Sobre as autoras 
Psicologia, Rua Ramiro Barcelos, 2600/104, CEP 90035.003, Porto Alegre, RS. Fone: (51) 3165150, Fax: (51) 3304797. E-mail: CEP_RUA@vortex.ufrgs.br. 